\title{
Arginine vasopressin in brains of free ranging striped mouse males following alternative reproductive tactics
}

\author{
Ivana Schoepf $^{1,2} \cdot$ Wiliam Kenkel $^{3} \cdot$ Carsten Schradin $^{1,4,5}$
}

Received: 19 February 2015/Accepted: 18 July 2015/Published online: 2 August 2015

(C) Japan Ethological Society and Springer Japan 2015

\begin{abstract}
Oxytocin (OT) and arginine vasopressin (AVP) are produced in the brain. Due to their importance in modulating social behaviour, these two neuropepetides have been extensively studied in captivity, yet few data are available from the field. Here we report the findings from an immunohistochemistry study, where we measured density of OT and AVP in different brain nuclei of wild African striped mice (Rhabdomys pumilio). Striped mice are socially flexible with both sexes being able to follow alternative reproductive tactics. Adult males can remain natally philopatric, or they can disperse and live solitarily as roamers or immigrate into a group and become breeders. Previous studies in captivity found no differences between solitary and group-living striped mice in AVPR1a expression, but solitary males had higher irAVP concentrations in the paraventricular nucleus and BNST. In the present study we tested whether the results obtained from captive studies could be replicated in the wild. We collected brains from 5 breeders, 9 philopatrics, and 3 roamers from a field site in South Africa and transported them to the USA for immunohistochemistry. Our results showed that roamers
\end{abstract}

Ivana Schoepf

bushbaby217@aol.com

1 School of Animal, Plant and Environmental Sciences, University of the Witwatersrand, Johannesburg, South Africa

2 Institute of Evolutionary Biology and Environmental Studies, University of Zurich, Winterthurerstrasse 190, 8057 Zurich, Switzerland

3 The Kinsey Institute, Indiana University, Bloomington, IN 47401, USA

4 Université de Strasbourg, IPHC-DEPE, 23 rue Becquerel, 67087 Strasbourg, France

5 CNRS, UMR7178, 67087 Strasbourg, France have higher irAVP concentrations in the BNST than philopatrics, which leads us to predict for future experimental studies that roamers will be able to increase AVP secretion in the brain when becoming group-living.

Keywords Social flexibility - Testosterone · Corticosterone - Brain mass - Intra-specific variation in social organisation

\section{Introduction}

Oxytocin (OT) and arginine vasopressin (AVP) are neuropeptides secreted in the brain and are causally implicated in regulating social behaviour (Bales et al. 2006; Carter 1998). Functional connections among brain regions of the social behaviour network (SBN) regulate phenotypic variation in behaviour. AVP and OT are produced and secreted by neurons in several areas of the SBN including the medial bed nucleus of the stria terminalis (BNST), the supra-optic nucleus (SON) and the paraventricular nucleus (PVN), with well-documented effects on social behaviours (Caldwell et al. 2008; Goodson and Kabelik 2009). AVP has been specifically implicated in male-male aggression (Ferris et al. 1986), social recognition (Dantzer et al. 1988) and social bonding (Winslow et al. 1993). The SON is involved in the regulation of emotional reactivity and mobilization to a variety of stressors (Landgraf et al. 1998). The PVN is of particular importance in the synthesis and release of neuropeptides into brain areas regulating behavioural and stress reactivity. For example, peptide containing neurons from the PVN project into both the basal forebrain and the brainstem (Sawchenko and Swanson 1982). AVP from the PVN has been associated with increased anxiety, and in response to stressors, can act as a 
secretagogue for ACTH release. These neuropeptides and associated changes in their receptors have been associated with species, population and individual differences in social behaviour (Cushing et al. 2001; Heckel and Fink 2008; Solomon et al. 2009). Detailed studies under controlled laboratory settings have shown how neuropeptides and their receptors are potent modulators of social behaviour in laboratory rodents of the genus Microtus (Young 2009; Carter 1998; Young et al. 1999). However, not much is known about how variation in neuropeptides is associated with variation in social behaviour in free-ranging animals.

In the last 5-10 years, several important field studies have investigated the variation in the distribution of AVP and OT neuropeptide receptors. For example, the groupliving colonial tuco-tuco (Ctenomys sociabilis) has been shown to differ significantly from the solitary living Patagonian tuco-tuco (Ctenomys haigi) in both AVPR1a and OTR binding in different areas of the forebrain (Beery et al. 2008). Several studies were performed to understand the influence of neuropeptides on sociality in prairie voles (Microtus ochrogaster), specifically to compare solitary wanderers and group-living socially monogamous males. However, variation in the expression of AVPR1a did not differ between males' social tactics, but were rather related to space use (independent of reproductive tactic; Ophir et al. 2008b). In contrast, monogamous males were found to express higher OTR density in the nucleus accumbens than other males, while OTR distribution in the hippocampus was related to space use (Ophir et al. 2012). Furthermore, the genetic background of this variation was studied by measuring the length of microsatellite DNA within the regulatory region of the gene (avprla) encoding for AVPR1a. However, no evidence was found that avpr1a genotype of males predicts variation in social monogamy measured in field enclosures, but avpr1a genotype significantly correlated with the number of females a male mated with and the total number of offspring sired (Solomon et al. 2009). Another study found significant effects of avpr1a allele length on V1aR expression in brain areas playing a role in pair-bond formation, but these effects did not represent alternative reproductive tactics nor reproductive success (Ophir et al. 2008a). Overall, field studies and studies in field enclosures revealed a complex pattern of AVPR1a expression and its underlying genetics.

AVPR1a is only one of two key factors determining neuropeptides' influence on social behaviour. The other one is, of course, the neuropeptide itself. It is important to understand where AVP is produced, in what quantities, and when and how much is released. To our knowledge, no field study has measured the neuropeptides themselves in the brains of mammals. Here we present the first field data on this and compare them with previous findings on the same species from studies done in captivity. We studied African striped mice (Rhabdomys pumilio), a species in which males can follow one of three alternative reproductive tactics (ARTs) that are known to differ in hormone levels (Schradin 2008a; Schradin et al. 2009a; Schradin and Yuen 2011; Schradin et al. 2012). Territorial breeding males are the heaviest with the highest reproductive success (Schradin and Lindholm 2011). They have high prolactin and testosterone, but low corticosterone levels. Typically, breeding males immigrate into groups of communally breeding females to mate, and they show high amounts of paternal care (Schradin and Pillay 2003). Adult males born within the group remain natally philopatric and have low testosterone and prolactin, but high corticosterone levels (likely because of reproductive suppression) and show high amounts of allo-parental care (Raynaud and Schradin 2014). When philopatric males leave the natal group and do not manage to immigrate as breeding males into another group, they become solitary roamers with very high testosterone levels, but low prolactin and low corticosterone levels. Roamers have some reproductive success by mating with females from communal groups (being defended by a breeding male), but they do not show any parental care. Breeders have by far the highest reproductive success, philopatrics very low reproductive success, while roamers have intermediate reproductive success when population density is high, but high reproductive success when population density is low (Schradin and Lindholm 2011). Overall, striped mouse males exhibit significant differences in their social and reproductive behaviour, though the underlying neural mechanisms are not well understood.

In a previous study, the three male ARTs were mimicked in captivity (Schradin et al. 2009b). An adult philopatric male was kept together with his father and his family while another male from the same litter was removed and kept alone, thus mimicking the roaming tactic. The two males raised under different conditions showed similar endocrine profiles as those observed from the field (Schradin et al. 2009b). Particularly, singly kept males had much higher testosterone and lower corticosterone levels than their group-living philopatric brothers (Schradin et al. 2012, 2013, 2014). However, no differences were found in AVPR1a expression, indicating that the brains of singly housed males have a similar capacity to respond to AVP as group-living males (Schradin et al. 2014). Solitary-housed males had significantly higher levels of irAVP in the PVN compared to group-living males, with a trend $(p=0.06)$ for the BNST (Schradin et al. 2013). It was thus hypothesized that roamers are physiologically primed, and capable, to release AVP to a responsive brain, form social bonds and become territorial, thus quickly adopting the breeding tactic. So far no information exists about the 
levels of irAVP in free ranging male striped mice, and we do not know whether roamers in the field have higher levels of irAVP when compared to group-living striped mice. The aim of our study was thus to measure irAVP in brains from free ranging male striped mice and to test the hypothesis that roamers would have high irAVP concentrations in the PVN and BNST, as has been reported from captive studies. Additionally, we also measured irOT in the same brain areas, as OT often influences social behaviour in females and sometimes in males (Anacker and Beery 2013). OT seems especially relevant to social behaviours involving selectivity, social structure and aggression (Lee et al. 2009), making it a potential mediator of social behaviour in striped mice.

\section{Materials and methods}

\section{Study area and period}

Data were collected in the breeding season between September 2009 and January 2010 on a field site located on the farm Klein Goegap $\left(29^{\circ} 42.30^{\prime} \mathrm{S}-18^{\circ} 02.95^{\prime} \mathrm{E}\right)$ near Springbok in South Africa. All striped mice within the study area were identified and their social tactics (philopatric, breeder or roamer) determined using a combination of trapping, radio-tracking and behavioural observations as described in detail in Schradin et al. (2009a). Mice were trapped directly at their nests, sexed and weighed. Each mouse received a permanent ear-tag (National Band and Tag Co., Newport, KY, USA) as well as a temporary hair dye mark on its fur (Inecto Rapido, Pinetown, South Africa) to allow observers to recognize different individuals during behavioural observations. Behavioural observations were carried out directly at mice nests during peak activity times to determine the group's structure. Males fitted with radio-collars (Holohil, Carp, Ontario, Canada; $1.2-4.5 \mathrm{~g})$ were radio-tracked during the day to determine home ranges, and at night to determine sleeping sites and composition of sleeping groups. Males that slept together with other individuals were considered group-living (philopatric if they were in their natal group; breeders if it was not their natal group), whereas males that slept alone were considered roamers. Striped mice are considered adults at around 4 weeks of age when they reach sexual maturity and weigh more than $30 \mathrm{~g}$ (Schradin et al. 2009a). For our study, we considered only individuals that weighed at least $30 \mathrm{~g}$ and were more than 4 weeks old. Philopatric individuals were born during the previous breeding season or early in the breeding season of sampling. The age (in weeks) of each individual was determined using previously calculated growth curves based on the trapping history and body mass of that specific individual (Schradin et al. 2009a). All philopatrics selected for this study showed clear signs of sexual maturity (e.g. testes were fully descended in the scrotal sac; Schradin et al. 2012).

\section{Behavioural testing}

Behavioural tests were conducted on ten individuals: two breeders, three roamers, and five philopatrics. This was part of a removal experiment carried out to study the reasons for solitary living in striped mice (Schoepf and Schradin 2012a). Mice were captured directly at their nests in the early morning during their peak activity times and transported to the research station for testing. Tests were performed in a neutral presentation arena (Schoepf and Schradin 2012b). Each mouse was presented with a stimulus mouse taken from a captive colony, which is permanently maintained at the research station. Each focal mouse from the field was subjected to three different social tests: pup encounter, opposite-sex encounter and same-sex encounter. Same- and opposite-sex encounters lasted for $10 \mathrm{~min}$ whereas pup encounter tests lasted for $5 \mathrm{~min}$. The following behaviours were recorded: aggression, sniffing (measured as frequencies) and body contact (measured as duration). In addition, for opposite-sex and same-sex encounters, we recorded frequency of grooming; and for pup encounters, we recorded frequencies of licking and huddling. For all tests, we followed the same protocols previously used in the study of aggression in striped mice (Schradin et al. 2010; Schoepf and Schradin 2012b; Schradin and Pillay 2014). Most of the agonistic encounters involved chasing and threat displays, and as such none of the same-sex and opposite-sex encounter tests needed to be prematurely terminated. However, in one case, the pup encounter test had to be interrupted due to enhanced aggression from the focal individual. The test was terminated as soon as we saw the pup being pushed and thus before any biting could occur. In this way we assured that none of the individuals used in the tests received any physical injuries. All individuals used in the behavioural tests were thereafter blood and brain sampled. The study was carried out under license from the Department of Environment, Food and Agriculture of South Africa and received ethical clearance from the University of the Witwatersrand (AESC: 2007/38/04).

\section{Brain and blood sampling}

Mice were trapped directly at their nests in the early morning as they emerged to bask, and a blood sample was taken within 3 min of the mouse entering a trap. Blood samples were collected using the sublingual method (Heimann et al. 2009) and were transported to the research station where they were centrifuged and the resulting 
serum stored in different aliquots and frozen. Two samples were obtained from breeders, eight from philopatrics and three from roamers.

After blood sampling, mice were returned to their traps and immediately taken to the research station where they were euthanized and their brains extracted. Brain tissue was removed and kept at room temperature in $4 \%$ paraformaldehyde with slow stirring for passive perfusion. Paraformaldehyde was changed after $10 \mathrm{~min}, 2$ and $3 \mathrm{~h}$. Brains were stored for $36 \mathrm{~h}$ at $4{ }^{\circ} \mathrm{C}$ in $4 \%$ paraformaldehyde and transferred into $20 \%$ sucrose solution, which was changed after 36 h. Altogether, we obtained brain samples from five breeders, nine philopatrics and three roamers.

\section{Hormone assays}

Blood samples were analysed at the University of Zurich. Commercial kits (EIA) from IBL Hamburg were used for both testosterone and corticosterone. Procedures followed those from the kit manual. However, due to very high corticosterone levels, samples were diluted 1:50. All measurements were well within the standard curve of the assay. The kits were previously validated for measurements of hormones in striped mouse serum by demonstrating that serial dilution of striped mouse sample pools (two for each hormone) paralleled the standard curve (Schradin 2008b). Intra- and inter-assay variability was determined with pools from striped mice serum. For corticosterone, intra-assay variability was $6.4 \%$ and inter-assay variability was $11.1 \%$. For testosterone, intra-assay variability was $3.3 \%$ and inter-assay variability was $11.4 \%$.

\section{Immunohistochemistry}

Brains were sectioned at $30 \mu \mathrm{m}$. Every third slice was reserved for immunohistochemical analysis of a particular antigen (i.e. AVP or OT). Free-floating sections were rinsed 6 times for $10 \mathrm{~min}$ each with potassium phosphatebuffered saline (KPBS). Sections then were incubated in $1 \%$ sodium borohydride for $20 \mathrm{~min}$. After six washes of 6 min each in KPBS, sections were incubated in $0.014 \%$ phenylhydrazine for $15 \mathrm{~min}$. Tissues were rinsed 6 times for $10 \mathrm{~min}$ each in KPBS. Sections were incubated in primary antibody (anti AVP from MP Biomedicals; anti OT generously donated and validated by Mariana Morris; Morris et al. 1980) and used at a concentration of $1: 100,000$ (diluted in KPBS + $0.4 \%$ Triton X-100; Grippo et al. 2007; Kenkel et al. 2012) for $1 \mathrm{~h}$ at room temperature, and incubated for $42 \mathrm{~h}$ at $4{ }^{\circ} \mathrm{C}$. Sections were rinsed 10 times for 6 min each with KPBS and afterwards incubated for $1 \mathrm{~h}$ at room temperature in anti-rabbit $\mathrm{IgG}$ (Vector Laboratories; 1:600). Sections were rinsed 5 times for $50 \mathrm{~min}$ with $\mathrm{KPBS}$, and incubated in $\mathrm{A} / \mathrm{B}$ solution
(Vector Laboratories; $45 \mathrm{ml} \mathrm{A,} 45 \mathrm{ml} \mathrm{B}$ per $10 \mathrm{ml}$ KPBS + $0.4 \%$ Triton X-100) for $1 \mathrm{~h}$. Sections were rinsed 3 times in KPBS for 5 min each and 3 times in Trisbuffered saline for $5 \mathrm{~min}$ each. After adding of $41.5 \mu \mathrm{l}$ of $\mathrm{H}_{2} \mathrm{O}_{2}$, both AVP and OT were visualized by immediate incubation in diaminobenzadine (DAB) dissolved in Trisbuffered saline, for $15 \mathrm{~min}$ at room temperature, and were rinsed 3 times with Tris-buffered saline and 3 times with KPBS (5 min each). Stained sections were mounted on gelatin-coated slides, air-dried, dehydrated in a series of ethanol dilutions, cleared with Histoclear (National Diagnostics), and protected with cover slips using Histomount mounting medium (National Diagnostics). Images were captured using a Nikon Eclipse E 8007 microscope (Nikon, Tokyo, Japan) mounted with a sensi-cam camera and analysed with IP Lab 3.7 computer software (Scanalytics Inc., Fairfax, VA, USA). The density of AVP- and OT-immunoreactive (ir) cell bodies was determined from pictures taken at $20 \times$ using Image $\mathrm{J}$ software (NIH, USA). We used a $688 \times 520$-pixel image size with 1 dpi and a magnification of 16-bit depth changed to 8-bit depth for analysis. In our experience, optical density is a more sensitive measure than cell counts. Whereas cell counting relies on neurons changing whether or not they synthesize the target of interest, optical density can semi-quantitatively gauge differences in synthesis. Additionally, optical density picks up on immunoreactive fibres and cell processes, which cell counting does not. Measurements were taken from selected brain areas of the "social behaviour network" that have previously been implicated in social behaviour (Caldwell et al. 2008; Goodson and Kabelik 2009): PVN, BNST, and SON (Fig. 1). OT was measured in an area of 112,500 pixels in the $\mathrm{PVN}$, in the entire area of the SON, while the number of OT-ir containing cells was counted in the BNST. AVP was measured in an area of 112,500 pixels in the PVN, and in the entire slide in the BNST and the SON. Most animals had more than one slice for a given brain nucleus. In this study a single representative slice for each individual, which showed the highest binding, was used for analysis. We used sections that were anatomically matched and were as close as possible to the middle of each brain nucleus. All analyses were conducted by an experimentally blinded observer.

\section{Statistics}

The software Instat (GraphPad) was used for all statistical analysis. Data were tested for normality using the ShapiroWilk test. ANOVA followed by the Tukey-Kramer multiple comparison test (q) was used to compare tactics. Percentage data, though bounded by 0.0 and $100.0 \%$, were treated like normally distributed data if their distribution did not differ significantly from normal. Data are presented 


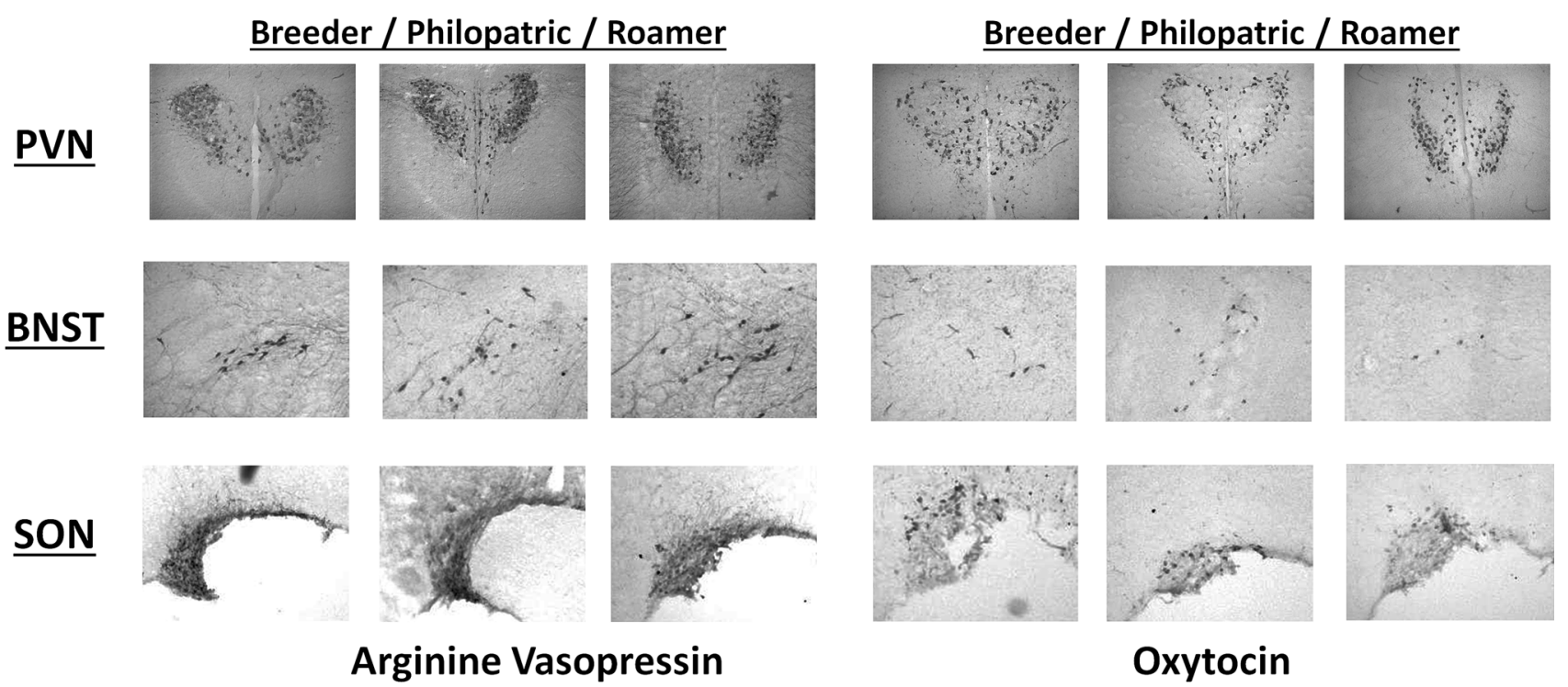

Fig. 1 Images of the distribution of irAVP (left) and irOT (right) in different brain areas of wild male striped mice belonging to three alternative reproductive tactics (breeder, philopatric or roamer)

as mean \pm standard deviation. Spearman correlation coefficients $\left(r_{\mathrm{s}}\right)$ were calculated to test for correlations between physiological and behavioural variables.

\section{Results}

\section{Body mass and sexual maturity}

Breeders $(55.6 \pm 11.2 \mathrm{~g})$ were of similar weight to roamers $(54.7 \pm 6.4 \mathrm{~g})$, but both were heavier than philopatrics $(31.6 \pm 2.8 \mathrm{~g}$; both $p<0.001$; Table 1$)$. These differences were mirrored in significant differences in total brain weight. Breeders $(0.74 \pm 0.07 \mathrm{~g})$ and roamers $(0.76 \pm 0.03 \mathrm{~g})$ did not differ but had heavier brains than philopatrics $(0.66 \pm 0.01 \mathrm{~g}$; both $p<0.05)$. When brain mass was corrected for body mass, philopatrics $(2.17 \pm 0.23 \%)$ had relatively larger brains than breeders $(1.36 \pm 0.22 \% ; p<0.001)$ and roamers $(1.39 \pm 0.11 \%$; $p<0.001)$.

\section{Endocrine differences}

For breeding males, blood samples were only available from two individuals: too few for statistical analysis. The two breeders had $0.41 \pm 0.08 \mathrm{ng} / \mathrm{ml}$ testosterone and $597 \pm 505 \mathrm{ng} / \mathrm{ml}$ corticosterone. Roamers tended to have higher testosterone levels than philopatrics $(0.45 \pm 0.29 \mathrm{ng} / \mathrm{ml}$ versus $0.18 \pm 0.17 \mathrm{ng} / \mathrm{ml}, t$ test, $\left.t_{9}=1.972, p=0.08\right)$ and had significantly lower corticosterone levels than philopatrics $(749 \pm 281 \mathrm{ng} / \mathrm{ml}$ versus $\left.1099 \pm 211 \mathrm{ng} / \mathrm{ml} ; t_{9}=2.267, p<0.05\right)$.

\section{Neuroendocrine differences}

irAVP in the SON did not differ between tactics, while there was a trend $(p=0.06)$ for the PVN (Table 2). In the PVN, the mean value was highest for breeders, lowest for philopatrics, and intermediate for roamers. There was a significant difference for irAVP in the BNST, and roamers had the highest amount of irAVP (Table 2). We found

Table 1 Morphological parameters (mean values \pm SD) measured in the three alternative reproductive tactics studied in free-living male African striped mice

\begin{tabular}{|c|c|c|c|c|c|c|c|c|c|}
\hline & $n$ & Units & Breeders & Philopatrics & Roamers & $F, p$ & $\begin{array}{l}\text { Breeders- } \\
\text { philopatrics }\end{array}$ & $\begin{array}{l}\text { Breeders- } \\
\text { roamers }\end{array}$ & $\begin{array}{l}\text { Philopatrics- } \\
\text { roamers }\end{array}$ \\
\hline Body mass & $5,9,3$ & $\mathrm{~g}$ & $55.6(11.2)$ & $31.6(2.8)$ & $54.7(6.4)$ & $F_{2,14}=25.78 * * * *$ & $>* * *$ & & $<* * *$ \\
\hline Brain mass & $5,9,3$ & $\mathrm{~g}$ & $0.74(0.07)$ & $0.66(0.01)$ & $0.76(0.03)$ & $F_{2,14}=5.538^{*}$ & $>*$ & & $<*$ \\
\hline Brain mass/body mass & $5,9,3$ & $\%$ & $1.36(0.22)$ & $2.17(0.23)$ & $1.39(0.11)$ & $F_{2,15}=25.20 * * * *$ & $<* * *$ & & $>* * *$ \\
\hline
\end{tabular}

$F$ and overall $p$ values are provided, and the direction of significant differences between groups are marked in bold and by sign $(* p<0.05$; $* * p<0.01 ; * * * p<0.001)$

$n$ number of individuals studied 
Table 2 Neuroendocrine parameters (mean values \pm SD) measured in the three alternative reproductive tactics studied in free-living male African striped mice

\begin{tabular}{|c|c|c|c|c|c|c|c|c|c|}
\hline & $n$ & Units & Breeders & Philopatrics & Roamers & $F, p$ & $\begin{array}{l}\text { Breeders- } \\
\text { philopatrics }\end{array}$ & $\begin{array}{l}\text { Breeders- } \\
\text { roamers }\end{array}$ & $\begin{array}{l}\text { Philopatrics- } \\
\text { roamers }\end{array}$ \\
\hline $\begin{array}{l}\text { AVP PVN/ } \\
\text { brain mass }\end{array}$ & $4,8,3$ & stained/g & $26929(6897)$ & $18870(3994)$ & $24323(5978)$ & $\begin{array}{c}F_{2,14}=3.528 \\
p=0.06\end{array}$ & $>?$ & & $<?$ \\
\hline $\begin{array}{r}\text { AVP BNST/ } \\
\text { brain mass }\end{array}$ & $5,9,3$ & stained/g & $755(262)$ & 574 (319) & 1184 (295) & $F_{2,14}=4.660^{*}$ & & $<?$ & $<*$ \\
\hline AVP SON & $5,9,3$ & stained/g & 1659 (1475) & $1455(533)$ & 2378 (699) & $\begin{array}{c}F_{2,14}=1.123 \\
p=0.35\end{array}$ & & & \\
\hline $\begin{array}{l}\text { OT PVN/ } \\
\text { brain mass }\end{array}$ & $5,9,3$ & stained/g & 7075 (2725) & 3216 (1014) & $6534(2002)$ & $F_{2,14}=8.709^{* *}$ & $>* *$ & & $<*$ \\
\hline OT BNST & $5,8,3$ & $\begin{array}{l}\text { no. stained } \\
\text { cells }\end{array}$ & $9.6(4.7)$ & $11.5(4.2)$ & $9.7(5.0)$ & $\begin{array}{c}F_{2,13}=0.34 \\
p=0.72\end{array}$ & & & \\
\hline OT SON & $3,9,3$ & stained/g & $111(141)$ & $94(91)$ & $82(87)$ & $\begin{array}{c}F_{2,12}=0.06 \\
p=0.94\end{array}$ & & & \\
\hline
\end{tabular}

$F$ and overall $p$ values are provided, and the direction of significant differences between groups are marked in bold and by sign $(* p<0.05$; $* * p<0.01)$

$n$ number of individuals measured

significant differences for OT concentration in the PVN, with breeders and roamers having higher concentrations than philopatrics (Table 2). There was no indication for a difference in the BNST ( $p>0.7$; Table 2$)$ or in the SON $(p=0.94$, Table 2).

\section{Physiology and behaviour}

Table 3 summarizes the correlation matrix between the physiological factors and the measured behaviours. This correlation matrix provides no evidence for relationships between physiology and behaviour. The data showed only one single significant relationship which, after Bonferroni correction, did not remain significant.

Sample sizes were too small for a statistical comparison of behaviour between the three tactics. On a narrative basis, when presented with another smaller male, both breeders and roamers showed mild aggression, while philopatrics showed more amicable behaviour (body contact). When presented with a female, aggression was mainly absent and all three tactics showed amicable behaviours. Breeders showed amicable behaviours towards pups, which were ignored by philopatrics, while roamers either ignored pups or showed mild aggression. None of the aggressive encounters resulted in mice biting each other, or in injuries.

\section{Discussion}

This is, to our knowledge, the first field study measuring neuropeptides in the brains of a sociable mammal with ARTs. Collecting brain samples in the field in South Africa

Table 3 Correlations between physiological factors and behaviour (tested in the neutral presentation arena)

\begin{tabular}{|c|c|c|c|c|c|}
\hline \multirow[t]{3}{*}{ Physiological variable } & \multicolumn{5}{|l|}{ Behavioural variable } \\
\hline & \multicolumn{2}{|l|}{ Opposite sex } & \multicolumn{2}{|l|}{ Same sex } & \multirow{2}{*}{$\begin{array}{l}\text { Pup } \\
\text { Lick and huddle }\end{array}$} \\
\hline & Body contact & Aggression & Body contact & Aggression & \\
\hline AVP PVN $(N=9)$ & $r_{\mathrm{s}}=0.03 p=0.95$ & $r_{\mathrm{s}}=-0.27 p=0.46$ & $r_{\mathrm{s}}=0.05 p=0.88$ & $r_{\mathrm{s}}=0.30 p=0.44$ & $r_{\mathrm{s}}=0.59 p=0.097$ \\
\hline $\operatorname{AVP} \operatorname{BNST}(N=10)$ & $r_{\mathrm{s}}=0.33 p=0.35$ & $r_{\mathrm{s}}=-0.06 p=0.87$ & $r_{\mathrm{s}}=0.31 p=0.39$ & $r_{\mathrm{s}}=0.09 p=0.81$ & $r_{\mathrm{s}}=0.44 p=0.20$ \\
\hline AVP SON $(N=10)$ & $r_{\mathrm{s}}=-0.15 p=0.68$ & $r_{\mathrm{s}}=0.29 p=0.41$ & $r_{\mathrm{s}}=-0.12 p=0.76$ & $r_{\mathrm{s}}=0.16 p=0.66$ & $r_{\mathrm{s}}=0.34 p=0.35$ \\
\hline OT PVN $(N=10)$ & $r_{\mathrm{s}}=-0.36 p=0.30$ & $r_{\mathrm{s}}=0.52 p=0.12$ & $r_{\mathrm{s}}=0.31 p=0.39$ & $r_{\mathrm{s}}=0.48 p=0.17$ & $r_{\mathrm{s}}=0.44 p=0.20$ \\
\hline OT BNST $(N=10)$ & $r_{\mathrm{s}}=0.40 p=0.25$ & $r_{\mathrm{s}}=-0.06 p=0.87$ & $r_{\mathrm{s}}=0.29 p=0.41$ & $r_{\mathrm{s}}=0.15 p=0.68$ & $r_{\mathrm{s}}=0.08 p=0.81$ \\
\hline OT SON $(N=9)$ & $r_{\mathrm{s}}=-0.36 p=0.34$ & $r_{\mathrm{s}}=0.55 p=0.13$ & $r_{\mathrm{s}}=-0.20 p=0.61$ & $r_{\mathrm{s}}=-0.22 p=0.55$ & $r_{\mathrm{s}}=-0.73 p=0.03$ \\
\hline Cort $(N=9)$ & $r_{\mathrm{s}}=0.56 p=0.12$ & $r_{\mathrm{s}}=-0.41 p=0.27$ & $r_{\mathrm{s}}=0.24 p=0.11$ & $r_{\mathrm{s}}=0.05 p=0.91$ & $r_{\mathrm{s}}=-0.06 p=0.88$ \\
\hline Testo $(N=9)$ & $r_{\mathrm{s}}=-0.32 p=0.39$ & $r_{\mathrm{s}}=0.55 p=0.13$ & $r_{\mathrm{s}}=-0.22 p=0.58$ & $r_{\mathrm{s}}=0.18 p=0.64$ & $r_{\mathrm{s}}=0.28 p=0.46$ \\
\hline
\end{tabular}

Original statistics without Bonferroni correction are presented to give an overall picture. One single uncorrected significant correlation $(p<0.05)$ is marked in bold, but after Bonferroni correction, this did not remain significant 
is challenging, especially if males of three ARTs have to be considered. During our field season, very few roaming males were present. As a consequence, the sample size and statistical power of our study is low. Importantly, the results can be put in context with more detailed studies on the same species in captivity, predicting high irAVP concentrations in the brains of solitary roamers, which may be able to secrete this neuropeptide when switching to a social tactic (Schradin et al. 2013, 2014). Overall, our field study validates previous findings from captivity, indicating that roamers have high irAVP concentrations in different areas of the SBN.

Roamers are known to have the highest testosterone levels, while philopatrics have the highest corticosterone levels (Schradin et al. 2009a). The results of the present study are in agreement with these previous findings. Interestingly, roamers were of similar body size to breeders, indicating that in our current study both tactics had similar reproductive success (Schradin and Lindholm 2011). Accordingly, absolute and relative brain mass of breeders and roamers were similar. As expected (Schradin et al. 2009b), males of the subordinate philopatric tactic were smaller and had lighter brains. However, relative to body mass, philopatrics had the largest brains, indicating that they were still growing, as sub-adult mammals typically have relatively larger brains to their body size (Leigh 2004).

Roamers had significantly higher levels of irAVP in the BNST compared to philopatrics, with high levels also measured in the PVN. This is in agreement with previous captive studies where singly housed males, representing roamers, had significantly higher irAVP levels in both the BNST and PVN when compared to group-living breeders and philopatrics (Schradin et al. 2013). In another study, it was found that singly housed males do not differ in the expression of AVPR1a from group-living males (Schradin et al. 2014). Roamers have thus sufficient stored AVP in nuclei of the SBN that they might be able to quickly secrete when changing from a solitary to a group-living tactic (Schradin et al. 2013, 2014). The combined results of these studies lead us to predict for future experimental studies that roamers might be able increase AVP secretion when becoming social. An increased amount of AVP secretion could either lead to an increase or a decrease in measurable irAVP in these brain nuclei. We therefore propose our current ideas as one possible interpretation. Here, we demonstrated that the captive scenario reflects the field: solitary roamers have high concentrations of irAVP in the cells of the SBN. Thus, singly housed males studied in captivity are a good model to mimic solitary living roamers in the field. It would be important to validate this hypothesis in the future and to measure whether solitary housed males can increase AVP secretion from the SBN when they are paired and start forming social bonds.

Both breeders and roamers had greater irOT in the PVN relative to philopatrics. These results agree with similar results found in the prairie vole, where reproductive experience resulted in increased OT levels in the PVN in males (Kenkel et al. 2014). The lack of difference between breeders and roamers suggests this may be more closely related to sexual experience than social behaviours.

We had data on social behaviour from standardised tests with 10 males following the three ARTs. However, correlating these social behaviour scores with our physiological measures did not provide evidence for relationships between neuropeptides and social behaviour. Neuropeptides play an important role in regulating amicable behaviours towards group members. In our tests, stimulus animals were always unknown strangers. Therefore, the context of the tests might have been unsuitable for answering the question of whether neuropeptides regulate social behaviour towards group members. Future studies should use familiar individuals as stimulus animals, which in the case of roamers could be females from groups within their home range.

Results from standardised experiments conducted in captivity need validation from the field, to ensure that the phenomena studied are representative of natural conditions and are not laboratory artefacts (Brown 1993). In spite of the low sample size, our results are largely in agreement with previous, more detailed, studies conducted in captivity, indicating high levels of irAVP in the SBN of solitary males. Future studies in captivity should test the hypothesis that solitary males secrete AVP from the BSN when they are forming social bonds and become group-living.

Acknowledgments We thank the Department of Tourism, Environment and Conservation of the Northern Cape for research permits, and the manager and staff of the Goegap Nature Reserve for their support. This study was made possible by the administrative and technical support of the Succulent Karoo Research Station (registered South African NPO 122-134), at which field site the data were collected. For help in the field, we thank C.H. Yuen (Research Station Manager). We are thankful to C.S. Carter for important comments. Funding was provided by the Swiss National Science Foundation (31003A-135770/1). Animal ethical clearance was provided by the University of the Witwatersrand, Johannesburg, South Africa (No. 2004/87/2A, 2005/82/4, and 2006/3/03).

\section{References}

Anacker AM, Beery AK (2013) Life in groups: the roles of oxytocin in mammalian sociality. Front Behav Neurosci 7:185

Bales KL, Kramer KM, Lewis-Reese AD, Carter CS (2006) Effects of stress on parental care are sexually dimorphic in prairie voles. Phys Behav 87:424

Beery AK, Lacey EA, Francis DD (2008) Oxytocin and vasopressin receptor distributions in a solitary and a social species of tuco- 
tuco (Ctenomys haigi and Ctenomys sociabilis). J Comp Neurol 507:1847

Brown RE (1993) Hormonal and experiential factors influencing parental behaviour in male rodents: an integrative approach. Behav Process 30:1

Caldwell HK, Lee H, Macbeth AH, WSY III (2008) Vasopressin: behavioral roles of an "original" neuropeptide. Prog Neurobiol 84:1

Carter CS (1998) Neuroendocrine perspectives on social attachment and love. Psychoneuroendocrinology 23:779

Cushing BS, Martin JO, Young LJ, Carter S (2001) The effects of peptides on partner preference formation are predicted by habitat in prairie voles. Horm Behav 39:48

Dantzer R, Koob GF, Bluthe RM, Moal ML (1988) Septal vasopressin modulates social memory in male rats. Brain Res 457:143-147

Ferris CF, Meenan DM, Axelson JF, Albers HE (1986) A vasopressin antagonist can reverse dominant/subordinate behavior in hamsters. Physiol Behav 38:135-138

Goodson JL, Kabelik D (2009) Dynamic limbic networks and social diversity in vertebrates: from neural context to neuromodulatory patterning. Front Neuroendocrinol 30:429

Grippo AJ, Gerena D, Huang J, Kumar N, Shab M, Ughreja R, Carter $S$ (2007) Social isolation induces behavioral and neuroendocrine disturbances relevant to depression in female and male prairie voles. Psychoneuroendocrinology 32:966-980

Heckel G, Fink S (2008) Evolution of the arginine vasopressin 1a receptor and implications for mammalian social behaviour. Prog Brain Res 170:321

Heimann M, Kasermann HP, Pfister R, Roth DR, Burki K (2009) Blood collection from the sublingual vein in mice and hamsters: a suitable alternative to retrobulbar technique that provides large volumes and minimizes tissue damage. Lab Anim 43:255

Kenkel WM, Paredes J, Yee RJ, Pournajafi-Nazarloo H, Bales KL, Carter CS (2012) Neuroendocrine and behavioural responses to exposure to an infant in male prairie voles. J Neuroendocrinol 24:874-886

Kenkel WM, Suboc G, Carter CS (2014) Autonomic. Behavioral and neuroendocrine correlates of paternal behavior in male prairie voles, Phys Behav

Landgraf R, Wotjak CT, Neumann ID, Engelmann M (1998) Release of vasopressin within the brain contributes to neuroendocrine and behavioral regulation. Prog Brain Res 119:201

Lee HJ, Macbeth AH, Pagani JH, Young WS (2009) Oxytocin: the great facilitator of life. Prog Neurobiol 88:127-151

Leigh SR (2004) Brain growth, life history, and cognition in primate and human evolution. Am J Primatol 62:139

Morris M, Stevens SW, Adams MR (1980) Plasma oxytocin during pregnancy and lactation in the cynomolgus monkey. BOR 23:782-787

Ophir AG, Campbell P, Hanna K, Phelps SM (2008a) Field tests of cis-regulatory variation at the prairie vole avpr1a locus: association with $\mathrm{V} 1 \mathrm{aR}$ abundance but not sexual or social fidelity. Horm Behav 54:694

Ophir AG, Wolff JO, Phelps SM (2008b) Variation in neural V1aR predicts sexual fidelity and space use among male prairie voles in semi-natural settings. Proc Natl Acad Sci USA 105:1249

Ophir AG, Gessel A, Zheng DJ, Phelps SM (2012) Oxytocin receptor density is associated with male mating tactics and social monogamy. Horm Behav 61:445

Raynaud J, Schradin C (2014) Corticosterone levels correlate with alloparental care in a sex-dependent manner in African striped mice, Rhabdomys pumilio. Ethology 121:57-67
Sawchenko PE, Swanson LW (1982) Immunohistochemical identification of neurons in the paraventricular nucleus of the hypothalamus that project to the medulla or to the spinal cord in the rat. J Comp Neurol 205:260

Schoepf I, Schradin C (2012a) Better off alone! Reproductive competition and ecological constraints determine sociality in the African striped mouse (Rhabdomys pumilio). J Anim Ecol $81: 649$

Schoepf I, Schradin C (2012b) Differences in social behaviour between group-living and solitary African striped mice Rhabdomys pumilio. Anim Behav 84:1159

Schradin C (2008a) Differences in prolactin levels between three alternative male reproductive tactics in striped mice (Rhabdomys pumilio). Proc R SocB 275:1047

Schradin C (2008b) Seasonal changes in testosterone and corticosterone levels in four social categories of a desert dwelling sociable rodent. Horm Behav 53:573

Schradin C, Lindholm AK (2011) Relative fitness of alternative male reproductive tactics in a mammal varies between years. J Anim Ecol 80:908

Schradin C, Pillay N (2003) Paternal care in the social and diurnal striped mouse (Rhabdomys pumilio): laboratory and field evidence. J Comp Psychol 117:317

Schradin C, Pillay N (2014) Absence of reproductive suppression in young adult female striped mice living in their natal family. Anim Behav 90:141-148

Schradin C, Yuen CH (2011) Hormone levels of male African striped mice change as they switch between alternative reproductive tactics. Horm Behav 60:676

Schradin C, Scantlebury M, Pillay N, König B (2009a) Testosterone levels in dominant sociable males are lower than in solitary roamers: physiological differences between three male reproductive tactics in a sociably flexible mammal. Am Nat 173:376

Schradin C, Schneider C, Yuen CH (2009b) Age at puberty in male African striped mice: the impact of food, population density and the presence of the father. Funct Ecol 23:1004-1013

Schradin C, Schneider C, Lindholm AK (2010) The nasty neighbour in the striped mouse (Rhabdomys pumilio) steals paternity and elicits aggression. Front Zool 7:19

Schradin C, Eder S, Müller K (2012) Differential investment into testes and sperm production in alternative male reproductive tactics of the African striped mouse (Rhabdomys pumilio). Horm Behav 61:686

Schradin C, Kenkel W, Krackow S, Carter C (2013) Staying put or leaving home: endocrine, neuroendocrine and behavioral consequences in male African striped mice. Horm Behav 63:136

Schradin C, Larke RH, Bales KL (2014) Growing up in the family or growing up alone influences behavior and hormones, but not arginine vasopressin receptor 1a expression in male African striped mice. Phys Behav 129:205

Solomon NG, Richmond AR, Harding PA, Fries A, Jacquemin S, Schaefer RL, Lucia KE, Keane B (2009) Polymorphism at the avpr1a locus in male prairie voles correlated with genetic but not social monogamy in field populations. Mol Ecol 18:4680

Winslow JT, Hastings N, Carter CS, Harbaugh CR, Insel TR (1993) A role for central vasopressin in pair bonding in monogamous prairie voles. Nature 365:545-548

Young L (2009) Love: neuroscience reveals all. Nature 457:148

Young LJ, Nilsen R, Waymire KG, MacGregor GR, Insel TR (1999) Increased affiliative response to vasopressin in mice expressing the V1a receptor from a monogamous vole. Nature 400:766 